Article

\title{
Intrapreneurial Self-Capital and Sustainable Innovative Behavior within Organizations
}

\author{
Mirko Duradoni ${ }^{1}$ [D and Annamaria Di Fabio ${ }^{2, *}$ \\ 1 Department of Information Engineering, University of Florence, 50139 Firenze, Italy; \\ mirko.duradoni@unifi.it \\ 2 Department of Education and Psychology (Psychology Section), University of Florence, 50135 Firenze, Italy \\ * Correspondence: adifabio@psico.unifi.it; Tel.: +39-(0)55-2055850; Fax: +39-(0)55-2756134
}

Received: 13 December 2018; Accepted: 4 January 2019; Published: 10 January 2019

\begin{abstract}
Innovative behavior is necessary to combat the 21st century's sustainability challenges, as well as to ensure organizations' longevity and success. Personality traits, such as extraversion, are strongly related to innovative behavior; nevertheless, such traits are not increasable through specific training. Intrapreneurial self-capital is a promising preventive resource to enhance people's capability to cope with innovations. On this basis, this study analyzed, in an explorative way, the relationship between extraversion, intrapreneurial self-capital, and innovative behavior, using a sample of 120 Italian workers. A mediation model was used to assess the effects of extraversion on innovative behavior and innovative implementation behavior (outcome variables) through intrapreneurial self-capital (conceived as an intervening mediator variable). The mediation analysis highlighted that intrapreneurial self-capital is correlated with both workers' innovative behavior and innovative implementation behavior. Therefore, implementing dedicated training on intrapreneurial self-capital could help organizations better address sustainability issues and achieve the Sustainable Development Goals introduced by the United Nations.
\end{abstract}

Keywords: innovative behavior; innovative implementation behavior; intrapreneurial self-capital; sustainability; sustainable development; innovation

\section{Introduction}

Our century is defined by rapid economic changes and continuous challenges such as globalization and unstable labor markets [1,2]. Innovation is fundamental in defining organizations' success and survival [3,4]. The importance of innovation in the workplace is even more crucial if we consider the framework offered by Industry 4.0, in which the psychological aspect of innovation is configured as an essential strategic element to compete in the global market [5]. Thus, it is not surprising that organizations actively search for workers who continually adapt to change by innovating. Historically, as stated by West and Farr [6], innovative work behavior was conceived as "the intentional introduction and application within a role, group or organization of ideas, processes, products or procedures, new to the relevant unit of adoption, designed to significantly benefit the individual, the group, the organization or wider society". At the individual level, innovative behavior was first studied as a one-dimensional construct [7]. However, more recently, the multidimensionality of innovative work behavior has been empirically confirmed [8]. Workers' innovative behavior has multiple facets that account for all the processes involved in innovation (from idea generation to subsequent idea implementation).

Innovative behavior is also strongly linked to sustainability. Innovation is a crucial aspect for organizations to face the challenges related to the Sustainable Development Goals, which were introduced by the United Nations (UN) [9], and to promote humane and productive organizations [10-14]. As studies 
regarding the psychology of sustainability and sustainable development have highlighted, innovative behaviors are necessary to meet sustainable project goals, as well as to achieve workers' growth and enrichment. Since many scholars agree that extraversion has a positive effect on employees' innovative behavior, organizations and human resource (HR) departments are paying particular attention to this personality trait in personnel selection and other HR decisions (e.g., career planning, resources allocation) [15]. The personality trait of extraversion appears to be related to the development of new techniques, work processes, services, and products [16]. Despite the evidence that links extraversion with workers' innovative behavior, personality is an intrinsic psychological feature that hardly changes over time, and it is traditionally considered to be stable [17] (i.e., it is not increasable through specific training). For this reason, scientific literature regarding innovation, especially at the individual level, has recently taken into consideration other constructs in which it is easier to intervene; among these, intrapreneurial self-capital has received increasing consideration. This construct was defined by Di Fabio [18] as a higher-order construct (i.e., a core of individual resources) that includes nine first-order constructs.

Intrapreneurial self-capital reflects the positive self-evaluation of one's own ability to be committed, to identify significant objectives, to feel in control over life events, to creatively solve problems, to change constraints into resources, to develop one's own skills, to apply decision-making skills to every aspect of life, and to make decisions carefully and adaptively $[18,19]$. Given such characteristics, intrapreneurial self-capital can enhance people's capability to cope with work-related changes and transition by means of innovative solutions [20]. Indeed, intrapreneurs frequently develop and implement new ideas within their organization, even when facing organizational change and conflicts [21], thus ensuring a successful innovation process, since novel ideas need to be acted upon and implemented [22,23].

In addition, recent studies have highlighted that intrapreneurial self-capital is correlated with extraversion $[20,24]$. Therefore, intrapreneurial self-capital seems to be related both to extraversion and employees' innovative behavior.

\section{Aim of the Study}

The aim of the present study relies on testing, in an explorative way, whether intrapreneurial self-capital could mediate the relationship between extraversion and individuals' innovative behavior, since other constructs have appeared to be able to do so [15]. Indeed, none of the previous studies have considered the relationship among these three variables at the same time. Using those same antecedents (i.e., extraversion and intrapreneurial self-capital), we also want to investigate whether the same theoretical relationship could be maintained to predict workers' innovative implementation behavior, since intrapreneurs seem specifically inclined toward implementation activities (i.e., planning in uncertain environments, studying circumstances in-depth, using information in a rational and strategic way) [25]. Nevertheless, the innovative implementation dimension has not received much attention in previous research. For this reason, we considered workers' innovation behavior not only as a one-dimensional construct [7], but also as a multi-faceted phenomenon, as acknowledged by the most recent scientific literature [22,26,27]. Therefore, we used the implementation starting activities dimension of the Innovative Behavior Inventory [8] to assess innovative implementation behavior, in which intrapreneurs seem to excel, and the total score to obtain a general picture of each individuals' innovative behavior. Differently from other studies that involve students, we wanted to test such relationships with a sample of workers.

The following hypotheses were formulated:

Hypothesis 1 (H1). Extraversion is positively correlated with both intrapreneurial self-capital and employees' innovative behavior.

Hypothesis 2 (H2). Intrapreneurial self-capital is positively correlated with employees' innovative behavior. 
Hypothesis 3 (H3). Intrapreneurial self-capital mediates the effect of extraversion on employees' innovative behavior.

Hypothesis 4 (H4). Intrapreneurial self-capital mediates the effect of extraversion on employees' innovative implementation behavior.

\section{Materials and Methods}

\subsection{Participants}

The participants of this study were 120 workers ( 85 females) employed as high school teachers in the Tuscany region, with an average age of 48 years (s.d. $=11.11$ ). A total of $91.67 \%$ have a master's degree, while $8.33 \%$ reported having a high school diploma. Participants' average length of service was 17.71 years (s.d. $=12.44$, Min $=1$ year, Max $=42$ years).

\subsection{Measures}

\subsubsection{Innovative Behavior Inventory (IBI)—Italian Version}

The IBI scale [8] consists of 23 items measured via a five-point Likert scale. For each of the statements presented, the respondents expressed their degree of agreement or disagreement, using the lower limit of the scale (i.e., 1) to express a strong disagreement, and the upper level (i.e., 5) to communicate maximum agreement. The 23 items of the IBI scale form seven dimensions: idea generation (e.g., I try new ways of doing things at work); idea search (e.g., I try to get new ideas from colleagues or business partners); idea communication (e.g., when I have a new idea, I try to persuade my colleagues about it); implementation starting activities (e.g., I develop suitable plans and schedules for the implementation of new ideas); involving others (e.g., when I have a new idea, I look for people who are able to push it through); overcoming obstacles (e.g., I am able to persistently overcome obstacles when implementing an idea); and innovation outputs (e.g., many things I came up with are used in our organization). The Cronbach's alpha coefficients for the IBI scale ranged from 0.61 to 0.88 . The psychometric properties of the Italian version of the IBI have previously been presented by Di Fabio and Duradoni [28]. The Italian version of IBI showed better reliability with Cronbach's alpha coefficients, ranging between 0.69 and 0.89 . The Italian version also showed good and appropriate indices of fit $\left(\chi^{2} / \mathrm{gdl}=2.45\right.$; Tucker-Lewis Index $(\mathrm{TLI})=0.90$; Confirmatory Fit Index $(\mathrm{CFI})=0.92$; Root Mean Square Error of Approximation (RMSEA) $=0.07$; Standardized Root Mean Square Residual $(\mathrm{SRMR})=0.05)$.

\subsubsection{HEXACO-60-Italian Version}

HEXACO [29] is a short personality inventory that consists of 60 items measured via a five-point Likert scale, ranging from $1=$ absolutely false to $5=$ absolutely true. The HEXACO assesses six dimensions: honesty/humility (e.g., I would not use flattery to get a raise or promotion at work, even if I thought it would succeed); emotionality (e.g., I would feel afraid if I had to travel in bad weather conditions); extraversion (e.g., I prefer jobs that involve active social interaction to those that involve working alone); agreeableness (e.g., I rarely hold a grudge, even against people who have badly wronged me); conscientiousness (e.g., I often push myself very hard when trying to achieve a goal); and openness to experience (e.g., I like people who have unconventional views). The reliability coefficients for the HEXACO scale ranged between 0.73 and 0.80 . The psychometric properties and the validity of the Italian version of HEXACO were presented by Di Fabio and Saklofske [30]. The reliability (Cronbach's alpha coefficients ranging from 0.76 and 0.78$)$ and the factorial structure $\left(\chi^{2} / \mathrm{gdl}=2.45\right.$; $\mathrm{TLI}=0.91 ; \mathrm{CFI}=0.92 ; \mathrm{RMSEA}=0.05 ; \mathrm{SRMR}=0.06$ ) of the Italian version were found to be in line with the original scale. 


\subsubsection{Intrapreneurial Self-Capital Scale (ISCS)—Italian Version}

The ISCS [18] uses a five-point Likert-type scale to measure the intrapreneurial self-capital construct. The scale is composed of 28 items and investigates self-evaluation, hardiness, creative self-efficacy, resilience, goal mastery, decisiveness, and vigilance aspects. The reported Cronbach's alpha coefficient for the ISCS total score is 0.86 . The psychometric properties of the scale were reported by Di Fabio [18]. Overall, the ISC showed appropriate dimensionality indices $\left(\chi^{2} / \mathrm{gdl}=1.43\right.$; $\mathrm{NNFI}=0.90 ; \mathrm{CFI}=0.90 ; \mathrm{RMSEA}=0.05 ; \mathrm{SRMR}=0.04)$.

\subsection{Procedure}

The questionnaires were administered to high school teachers in group sessions by trained psychologists, in line with the requirements of privacy and informed consent of Italian law (Law Decree DL-196/2003) and EU regulation (2016/699). Any participant could withdraw from the data collection session at any time. The scales were administered in counterbalanced order to control for order effects.

\subsection{Data Analysis}

We first verified the preconditions necessary for mediation analysis. For all the variables suitable for the mediation analysis, we excluded gender-related differences. Subsequently, we carried on regression procedures recommended by Hayes [31] for the assessment of mediation using PROCESS version 3.2 [32]. We selected a simple mediation model (i.e., theoretical model 4) to assess the causal effects of an independent variable $(\mathrm{X})$ on an outcome variable $(\mathrm{Y})$ through an intervening mediator variable (M). According to Hayes [31], in a simple mediation model, there are two possible pathways in which $X$ affects $Y$. The first path directly connects $X$ with $Y$, while the second links $X$ and $Y$ indirectly through $M$. We proceeded to estimate the effect sizes of the mediator (i.e., how much of the independent variable's effect was accounted for by the mediator) and of the entire model (i.e., direct and indirect pathways effects).

\section{Results}

\subsection{Descriptive Statistics}

Table 1 reports the descriptive statistics for the high school teacher sample. The data refer to all those dimensions involved in our data collection.

Table 1. Descriptive statistics.

\begin{tabular}{ccc}
\hline Scale & Variable & Average (s.d.) \\
\hline \multirow{3}{*}{ HEXACO } & Honesty/humility & $40.61(5.74)$ \\
& Emotionality & $33.35(5.14)$ \\
& Extraversion & $33.51(5.19)$ \\
& Agreeableness & $33.20(4.93)$ \\
& Conscientiousness & $37.08(6.02)$ \\
& Openness to experience & $35.91(5.70)$ \\
\hline \multirow{2}{*}{ IBI } & Idea generation & $3.84(0.72)$ \\
& Idea search & $3.90(0.63)$ \\
& Idea communication & $3.62(0.70)$ \\
& Implementation starting activities & $3.20(0.81)$ \\
& Involving others & $3.27(0.74)$ \\
ISCS & Overcoming obstacles & $3.39(0.68)$ \\
& Innovation outputs & $3.18(0.80)$ \\
& Total Score & $3.49(0.51)$ \\
\hline
\end{tabular}




\subsection{Mediation Analysis}

Correlations between personality traits, innovative behavior, and intrapreneurial self-capital were explored. In Table 2, we report the correlation matrix.

Table 2. Correlation matrix between HEXACO personality traits, innovative behavior, and intrapreneurial self-capital.

\begin{tabular}{cccc}
\hline Scale & Variable & IBI & ISC \\
\hline & Honesty/humility & -0.08 & $0.30^{* *}$ \\
& Emotionality & -0.17 & $-0.28^{* *}$ \\
EEXACO & Extraversion & $0.42^{* *}$ & $0.57^{* *}$ \\
& Agreeableness & -0.01 & $0.19^{*}$ \\
& Conscientiousness & 0.04 & $0.56^{* *}$ \\
& Openness to experience & $0.41^{* *}$ & $0.43^{* *}$ \\
\hline & $*: p \leq 0.05 ; * *: p \leq 0.01$. &
\end{tabular}

In line with our hypotheses, extraversion resulted as the most highly correlated personality trait with the variables of interest. Indeed, extraversion showed significant and robust correlations with the IBI total score (Pearson $r=0.42, p=0.001$ ) and the IBI implementation dimension (Pearson $r=0.30$, $p=0.001$ ), as well as with the ISCS score (Pearson $\mathrm{r}=0.57, p=0.001$ ). The IBI total score and the ISCS score were also related (Pearson $r=0.54, p=0.001$ ). Finally, intrapreneurial self-capital was shown to be positively correlated with innovative implementation behavior (Pearson $r=0.32, p=0.001$ ).

On this basis, we decided to perform two mediation analyses, using extraversion as our independent variable and intrapreneurial self-capital as the mediator, to predict both innovative behavior as a whole (Model 1) and its implementation component (Model 2). Figure 1 represents the relationship between extraversion and innovative behavior, with intrapreneurial self-capital as a mediator, while Table 3 shows the statistics related to each mediation path.

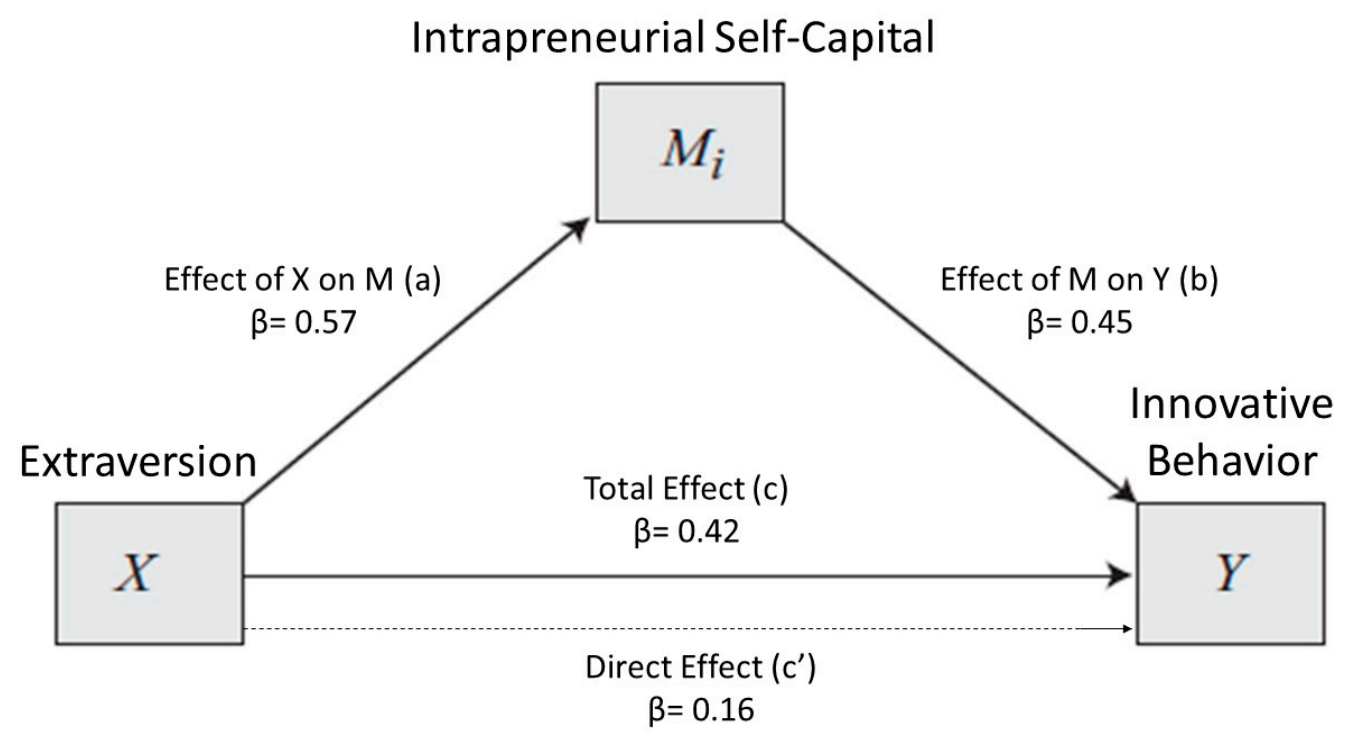

Figure 1. Model 1. Relationship between extraversion and innovative behavior, with intrapreneurial self-capital as a mediator. $\mathrm{k}^{2}$ Mediator Effect Size $=0.23$.

Consistent with our predictions, extraversion demonstrated a significant direct positive influence on innovative behavior (path c) and also affected it indirectly through intrapreneurial self-capital. However, the direct effect (path $c^{\prime}$ ) did not appear statistically significant. Highly extraverted individuals reported higher intrapreneurial self-capital (path a), and participants who had high 
scores in intrapreneurial self-capital appeared to behave in a more innovative way (path b). In Table 3, model effects indices are summarized.

Table 3. Model 1. Mediation analysis statistics.

\begin{tabular}{ccccc}
\hline & $\mathbf{F}$ & $\mathbf{d f}$ & $\boldsymbol{p .}$ & $\mathbf{R}^{\mathbf{2}}$ \\
\hline X predicts M & 57.63 & 1,118 & 0.001 & 0.33 \\
X and M predict Y & 25.91 & 2,117 & 0.001 & 0.31 \\
X predicts Y & 24.78 & 1,118 & 0.001 & 0.17 \\
\hline & Student t & df & $\boldsymbol{p}$. & Standardized $\boldsymbol{\beta}$ \\
\hline Path a & 7.59 & 118 & 0.001 & 0.57 \\
Path b & 4.74 & 117 & 0.03 & 0.45 \\
Path c' & 1.72 & 117 & 0.08 & 0.16 \\
Path c & 4.98 & 118 & 0.02 & 0.42 \\
\hline
\end{tabular}

As we can gather from Table 4 , the $23 \%$ of the variance in the innovative behavior score is explained by using intrapreneurial self-capital as a mediator. Meanwhile, the interaction of extraversion and intrapreneurial self-capital explains the $32 \%$ of the innovative behavior total score.

Table 4. Model 1. Effect indices.

\begin{tabular}{ccccccc}
\hline Total Effect & Direct Effect & $\begin{array}{c}\text { Indirect } \\
\text { Effect }\end{array}$ & $\begin{array}{c}\text { Par. Standardized } \\
\text { Indirect Effect }\end{array}$ & $\begin{array}{c}\text { Tot. Standardized } \\
\text { Indirect Effect }\end{array}$ & $\mathbf{k}^{2}$ & $\begin{array}{c}\text { Total Variance } \\
\text { Explained by Model }\end{array}$ \\
\hline 0.04 & 0.02 & 0.03 & 0.05 & 0.25 & 0.23 & 0.32 \\
\hline
\end{tabular}

For the second model, we proceeded as before, changing the output variable (i.e., implementation dimension). Figure 2 presents the graphical representation of Model 2, in which the relationship between extraversion and innovative implementation behavior is mediated by intrapreneurial self-capital. In Table 5, the model related statistics are shown.

\section{Intrapreneurial Self-Capital}

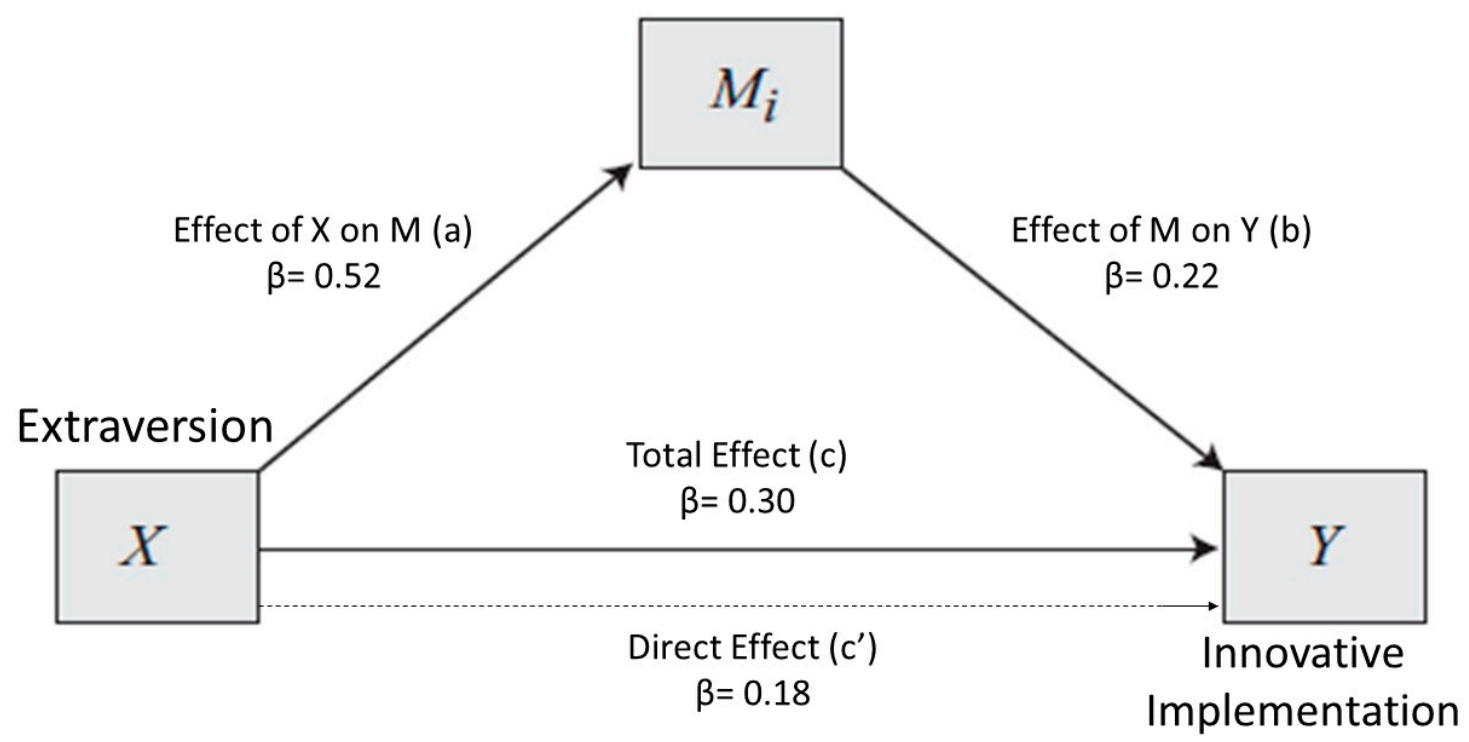

Figure 2. Model 2. Relationship between extraversion and innovative implementation behavior, with intrapreneurial self-capital as a mediator. $\mathrm{k}^{2}$ Mediator Effect Size $=0.08$. 
Table 5. Model 2. Mediation analysis statistics.

\begin{tabular}{ccccc}
\hline & $\mathbf{F}$ & $\mathbf{d f}$ & $\boldsymbol{p}$ & $\mathbf{R}^{\mathbf{2}}$ \\
\hline X predicts M & 28.05 & 1,118 & 0.001 & 0.19 \\
X and M predict $\mathrm{Y}$ & 7.68 & 2,117 & 0.001 & 0.12 \\
X predicts Y & 7.40 & 1,118 & 0.007 & 0.06 \\
\hline & Student t & df & $\boldsymbol{p}$. & Standardized $\boldsymbol{\beta}$ \\
\hline Path a & 5.30 & 118 & 0.001 & 0.52 \\
Path b & 2.75 & 117 & 0.007 & 0.22 \\
Path c' & 1.31 & 117 & 0.19 & 0.18 \\
Path c & 2.72 & 118 & 0.007 & 0.30 \\
\hline
\end{tabular}

In line with our prediction, intrapreneurial self-capital mediates the association between extraversion and innovative implementation behavior. The total effect (path c) of extraversion on innovative implementation behavior was significant; however, the direct effect that was conditional on the mediator was not statistically significant (path $\mathrm{c}^{\prime}$ ). Highly extraverted individuals reported higher scores on the intrapreneurial self-capital scale (path a), and teachers who had high scores in intrapreneurial self-capital seemed more willing and readier to implement new ideas (path b). Table 6 summarizes the model effects indices.

Table 6. Model 2. Effect indices.

\begin{tabular}{ccccccc}
\hline Total Effect & Direct Effect & $\begin{array}{c}\text { Indirect } \\
\text { Effect }\end{array}$ & $\begin{array}{c}\text { Par. Standardized } \\
\text { Indirect Effect }\end{array}$ & $\begin{array}{c}\text { Tot. Standardized } \\
\text { Indirect Effect }\end{array}$ & $\mathbf{k}^{2}$ & $\begin{array}{c}\text { Total Variance } \\
\text { Explained by Model }\end{array}$ \\
\hline 0.03 & 0.02 & 0.02 & 0.02 & 0.12 & 0.08 & 0.18 \\
\hline
\end{tabular}

As we can gather from Table 6 , around $8 \%$ of the variance in innovative implementation behavior is explained by using intrapreneurial self-capital as a mediator. Testing for the overall effects that extraversion, intrapreneurial self-capital, and their interaction have on innovative implementation behavior, we obtained a model global effect size of $18 \%$.

Finally, we also considered openness to experience as a possible predictor; however, the very low $r$-squared mediation effect obtained from the mediation analysis suggested that openness and ISC could act independently on innovative behavior.

\section{Discussion}

In general, the current study extended previous research by examining mediation models that explain employees' innovative behavior and assess the role of intrapreneurial self-capital as a mediator of extraversion among adult workers.

First, we confirmed the literature results concerning the relationships between extraversion, intrapreneurial self-capital, and employees' innovative behavior (H1) [15,24]. This study also explored and confirmed the results regarding the relationship between intrapreneurial self-capital and individual innovative behavior [21] (H2). The existence of such relationships was a necessary precondition to performing our mediation analysis.

Hypotheses 3 and 4 were also supported, revealing that extraversion's effect on employees' innovative behavior is mediated by intrapreneurial self-capital. Following the $\mathrm{k}^{2}$ interpretation of Preacher and Kelley [33], we found a large mediator effect size for Model 1 (i.e., output variable $=$ innovative behavior as a whole) and a medium mediator effect size for Model 2 (i.e., output variable $=$ innovative implementation behavior).

The fact that the direct effect in our mediation models (i.e., when the mediator is accounted for) became insignificant underlined even more how intrapreneurial self-capital can be a key factor in promoting innovative behavior [20], since a great part of the total effect of extraversion on innovative behavior and innovative implementation behavior appeared to pass through the mediator pathway. 
These indirect effects are explained by the fact that extraverted individuals are more likely to pursue innovation under incentives [15], which could be inherent in the innovation process itself, since highly extraverted individuals tend to conceive innovation as an opportunity for personal growth and as a way to increase their own resources (i.e., they have higher intrapreneurial self-capital) [34].

Unlike personality traits, intrapreneurial self-capital is increasable through specific training $[35,36]$ and could more easily be used within a primary prevention perspective (i.e., positive psychology) for the enhancement of workers' innovation potential [2,37-39]. In other words, workers can boost their innovation capabilities through specific training based on increasing their intrapreneurial self-capital. Nevertheless, our work still is exploratory and correlational (i.e., non-causal relationships are involved). Thus, future research should clarify whether causal relationships exist between these variables.

Notably, intrapreneurial self-capital is associated with eudaimonic well-being [19] in terms of social and psychological prosperity and promotes flourishing and resilient workers [20]. Other studies have highlighted how intrapreneurial self-capital provides benefits for career development (e.g., career self-efficacy, career decision-making) [18] and adaptive well-being (e.g., hope, acceptance of change) [24]. Therefore, enhancing intrapreneurial self-capital in a primary preventive perspective could have a much more wide and comprehensive effect on workers (i.e., helping them to more successfully face the unpredictable and dynamic environments of current organizations) than just increasing their innovative behavior.

Overall, our results appear useful and exploitable for human resources, organizational development, and career planning. Nevertheless, several limitations of this study need to be addressed. The results of the present study are not fully generalizable to all Italian workers in any line of work, since the participants were high school teachers from the Tuscany region. Future research should expand the investigation regarding the mediation effect of intrapreneurial self-capital on innovative behavior, involving workers from different geographical areas in Italy as well as from foreign countries, to address the cross-cultural invariance of our results. Moreover, our mediation models should be further tested, taking into account different types of workers. Future research should also consider other possible relationships between intrapreneurial self-capital and other constructs that are able to enhance innovative and sustainable behaviors. For instance, workplace relational civility [40] could potentially sustain and amplify the impact of intrapreneurial self-capital on innovative behavior (i.e., creating a work climate open to change and innovation). Also, sustainable leadership [12] should be taken into account in future studies as a possible way to increase intrapreneurial self-capital and thus innovative behavior.

Despite the aforementioned limitations, this study suggests that intrapreneurial self-capital could promote sustainable development within organizations $[10,13]$, due to its relation to innovative behavior. Intrapreneurial self-capital also appears particularly useful in achieving the transition from innovation idea generation to implementation. Acting upon workers' intrapreneurial self-capital could increase their innovative potential, thus favoring organizations' sustainable development and health. Furthermore, intrapreneurial self-capital could potentially introduce new psychological resources and strengths to better approach sustainability issues and achieve the Sustainable Development Goals put forth by the United Nations [41]. To meet sustainable project goals, organizations must seek innovative behavior and solutions. Enriching workers' ability to creatively solve problems and transform constraints into resources will sustain innovative behavior, in line with a new preventive pathway offered by the psychology of sustainability and sustainable development [41]. Even though the relationship between innovative behavior and sustainable development was not directly assessed in our study, a recent work [24] suggested that intrapreneurial self-capital is connected to well-being aspects which are in line with the Sustainable Development Goals (i.e., goal number three: good health and well-being; goal number eight: decent work and economic growth). In a primary preventive perspective, organizations must pay attention to promising psychological resources that could make a difference in terms of future concrete behaviors regarding sustainability issues. 
Author Contributions: Conceptualization, M.D. and A.D.F.; Data curation, M.D. and A.D.F.; Investigation, M.D. and A.D.F.; Methodology, M.D. and A.D.F.; Writing-original draft, M.D. and A.D.F.; Writing-review \& editing, M.D. and A.D.F.

Funding: This research received no external funding.

Conflicts of Interest: The authors declare no conflict of interest.

\section{References}

1. Blustein, D.L.; Kenny, M.E.; Di Fabio, A.; Guichard, J. Expanding the Impact of the Psychology of Working: Engaging Psychology in the Struggle for Decent Work and Human Rights. J. Career Assess. 2018. [CrossRef]

2. Di Fabio, A.; Kenny, M.E. From Decent Work to Decent Lives: Positive Self and Relational Management (PS\&RM) in the Twenty-First Century. Front. Psychol. 2016, 7. [CrossRef]

3. García-Goñi, M.; Maroto, A.; Rubalcaba, L. Innovation and motivation in public health professionals. Health Policy 2007, 84, 344-358. [CrossRef]

4. Anderson, N.; Potočnik, K.; Zhou, J. Innovation and Creativity in Organizations: A State-of-the-Science Review, Prospective Commentary, and Guiding Framework. J. Manag. 2014, 40, 1297-1333. [CrossRef]

5. Palazzeschi, L.; Bucci, O.; Di Fabio, A. Re-thinking Innovation in Organizations in the Industry 4.0 Scenario: New Challenges in a Primary Prevention Perspective. Front. Psychol. 2018, 9. [CrossRef] [PubMed]

6. West, M.A.; Farr, J.L. Innovation and Creativity at Work: Psychological and Organizational Strategies; John Wiley \& Sons: New York, NY, USA, 1990.

7. Scott, S.G.; Bruce, R.A. Determinants of Innovative Behavior: A Path Model of Individual Innovation in the Workplace. Acad. Manage. J. 1994, 37, 580-607.

8. Lukes, M.; Stephan, U. Measuring employee innovation: A review of existing scales and the development of the innovative behavior and innovation support inventories across cultures. Int. J. Entrep. Behav. Res. 2016, 23, 136-158.

9. United Nations About the Sustainable Development Goals. 2018. Available online: https:/ /www.un.org/ sustainabledevelopment/sustainable-development-goals / (accessed on 20 December 2018).

10. Di Fabio, A. Positive Healthy Organizations: Promoting Well-Being, Meaningfulness, and Sustainability in Organizations. Front. Psychol. 2017, 8. [CrossRef]

11. Di Fabio, A. The Psychology of Sustainability and Sustainable Development for Well-Being in Organizations. Front. Psychol. 2017, 8. [CrossRef]

12. Di Fabio, A.; Peiró, J.M. Human Capital Sustainability Leadership to Promote Sustainable Development and Healthy Organizations: A New Scale. Sustainability 2018, 10, 2413. [CrossRef]

13. Tetrick, L.E.; Peiró, J.M. Occupational Safety and Health. In Handbook of Occupational Health Psy-Chology; American Psychological Association: Worcester, MA, USA, 2012.

14. Peiró, J.M.; Rodríguez, I. Estrés laboral, liderazgo y salud organizacional. Papeles Psicól. 2008, 29 , 68-82.

15. Luo, Y.; Cao, Z.; Yin, L.; Zhang, H.; Wang, Z. Relationship between Extraversion and Employees' Innovative Behavior and Moderating Effect of Organizational Innovative Climate. NeuroQuantology 2018, 16. [CrossRef]

16. Abdullah, I.; Omar, R.; Panatik, S.A. A Literature Review on Personality, Creativity and Innovative Behavior. Int. Rev. Manag. Mark. 2016, 6, 177-182.

17. Costa, P.T.; McCrae, R.R. Four ways five factors are basic. Personal. Individ. Differ. 1992, 13, 653-665. [CrossRef]

18. Di Fabio, A. Intrapreneurial Self-Capital: A New Construct for the 21st Century. J. Employ. Couns. 2014, 51, 98-111. [CrossRef]

19. Di Fabio, A.; Gori, A. Neuroticism and flourishing in white collar workers: From self-esteem to intrapreneurial self-capital for adaptive outcomes. In Neuroticism: Characteristics, Impact on Job Performance and Health Outcomes; Psychology of Emotions, Motivations and Actions; Nova Science Publishers: Hauppauge, NY, USA, 2016; pp. 129-146. ISBN 978-1-63485-323-1.

20. Di Fabio, A.; Palazzeschi, L.; Bucci, O. In an Unpredictable and Changing Environment: Intrapreneurial Self-Capital As a Key Resource for Life Satisfaction and Flourishing. Front. Psychol. 2017, 8. [CrossRef]

21. Pinchot, G.; Pellman, R. Intrapreneuring in Action: A Handbook for Business Innovation; Berrett-Koehler Publishers: Oakland, CA, USA, 1999; ISBN 978-1-57675-061-2.

22. Jong, J.D.; Wennekers, S. Intrapreneurship; Conceptualizing Entrepreneurial Employee Behaviour; EIM Business and Policy Research: Zoetermeer, The Netherlands, 2008. 
23. Bledow, R.; Frese, M.; Anderson, N.; Erez, M.; Farr, J. A Dialectic Perspective on Innovation: Conflicting Demands, Multiple Pathways, and Ambidexterity. Ind. Organ. Psychol. 2009, 2, 305-337. [CrossRef]

24. Di Fabio, A.; Kenny, M.E. Intrapreneurial Self-Capital: A Key Resource for Promoting Well-Being in a Shifting Work Landscape. Sustainability 2018, 10, 3035. [CrossRef]

25. Lubkins, L.; Kans, K. Entrepreneurial Strategic Process; Elsevier: Oxford, UK, 2007.

26. Krause, D.E. Influence-based leadership as a determinant of the inclination to innovate and of innovation-related behaviors-An empirical investigation. Leadersh. Q. 2004, 1, 79-102. [CrossRef]

27. Jong, J.D.; Hartog, D.D. Measuring Innovative Work Behaviour. Creat. Innov. Manag. 2010, 19, $23-36$. [CrossRef]

28. Di Fabio, A.; Duradoni, M. The Innovative Behavior Inventory (IBI): Factorial structure and reliability of the Italian version. Counseling 2019, in press.

29. Ashton, M.C.; Lee, K. The HEXACO-60: A Short Measure of the Major Dimensions of Personality. J. Pers. Assess. 2009, 91, 340-345. [CrossRef] [PubMed]

30. Di Fabio, A.; Saklofske, D. HEXACO-60: First contribution to the validation of the Italian version. Counseling 2017, 10, 1-4.

31. Hayes, A.F. Introduction to Mediation, Moderation, and Conditional Process Analysis: A Regression-Based Approach; Guilford Press: New York, NY, USA, 2013.

32. Hayes, A.F. PROCESS: A Versatile Computational Tool for Observed Variable Mediation, Moderation, and Conditional Process Modeling. White Paper. 2012. Available online: http://www.afhayes.com/public/ process2012.pdf (accessed on 20 December 2018).

33. Preacher, K.J.; Kelley, K. Effect size measures for mediation models: Quantitative strategies for communicating indirect effects. Psychol. Methods 2011, 16, 93-115. [CrossRef] [PubMed]

34. Malaguti, E. Educarsi Alla Resilienza: Come Affrontare Crisi e Difficoltà e Migliorarsi; Edizioni Erickson: Trento, Italy, 2005; ISBN 978-88-7946-812-1.

35. Di Fabio, A.; Van Esbroeck, R. Intrapreneurial Self-Capital: A concept fitting a life-designing intervention. Couns. G. Ital. Ric. E Appl. 2016, 9. [CrossRef]

36. McIlveen, P.; Di Fabio, A. Intrapreneurial Self-Capital Training: A Case Study of an Italian University Student. In Narrative Interventions in Post-Modern Guidance and Career Counseling: A Review of Case Studies and Innovative Qualitative Approaches; Di Fabio, A., Bernaud, J.-L., Eds.; Springer International Publishing: Cham, Switzerland, 2018; pp. 197-209. ISBN 978-3-319-98300-4.

37. Hage, S.M.; Romano, J.L.; Conyne, R.K.; Kenny, M.; Matthews, C.; Schwartz, J.P.; Waldo, M. Best Practice Guidelines on Prevention Practice, Research, Training, and Social Advocacy for Psychologists. Couns. Psychol. 2007, 35, 493-566. [CrossRef]

38. Kenny, M.E.; Hage, S.M. The Next Frontier: Prevention as an Instrument of Social Justice. J. Prim. Prev. 2009, 30, 1-10. [CrossRef]

39. Di Fabio, A.; Kenny, M.E. Promoting Well-Being: The Contribution of Emotional Intelligence. Front. Psychol. 2016, 7. [CrossRef]

40. Di Fabio, A.; Gori, A. Assessing Workplace Relational Civility (WRC) with a New Multidimensional "Mirror" Measure. Front. Psychol. 2016, 7. [CrossRef]

41. Di Fabio, A.; Rosen, M.A. Opening the Black Box of Psychological Processes in the Science of Sustainable Development: A New Frontier. Eur. J. Sustain. Dev. Res. 2018, 2, 47. [CrossRef]

(C) 2019 by the authors. Licensee MDPI, Basel, Switzerland. This article is an open access article distributed under the terms and conditions of the Creative Commons Attribution (CC BY) license (http://creativecommons.org/licenses/by/4.0/). 